\title{
VALORACIÓN DE INVENTARIOS, SU INCIDENCIA JURÍDICA. MÉTODOS PARA SU ESTUDIO
}

Inventory Valuation, its Legal Incidence. Methods for your Study

\author{
María Luz Rodríguez Cosme, Dra. C. \\ Universidad de Oriente, Cuba \\ https://orcid.org/0000-0003-1617-1876 \\ mariluz@uo.edu.cu
}

Palabras claves: Violación, Regulación, Abogado.

Keywords: Violation, Regulation, Lawyer.
Recibido: 03 de marzo de 2021

Aceptado: 29 de abril de 2021

\section{RESUMEN}

Lesionar los bienes jurídicos de un tercero acarrea una responsabilidad derivada del acto ilegal. Esta relación también se manifiesta en el Derecho Laboral, entre el empleador y el empleado. Es frecuente que, en esta relación, se lesione el derecho de una de las partes, pero cuando la lesión se produce al patrimonio de una Empresa Estatal o particular por parte del trabajador, inicia para este un proceso de carácter laboral, civil y que en ocasiones llega a ser penal, en dependencia de la magnitud del hecho ocurrido. Por eso, el objetivo es reflexionar acerca de la violación del derecho laboral en Cuba. La determinación de la aplicación de una rama del Derecho u otra se basa en normas legales que establecen cuantías económicas de los bienes jurídicos lesionados. Para esta determinación, es necesario obtener el valor jurídico del bien lesionado, el que se determina mediante certificados avalados por la contabilidad, la que, a su vez, está regida por métodos de valoración de inventarios que ponderan el valor de todas las mercancías de similares características en almacén. Por tanto, en algunos casos, el valor obtenido de la contabilidad, no es valor real del bien según su factura de compra.

\begin{abstract}
The violation of the legal assets of a third party carries a liability arising from the illegal act. This relationship is also manifested in labor rights between the employer and the employee. It is common that in this relationship, the right of one of the parties is violated, but when the violation occurs involving the wealth of a State or private company by the employee, it can start a labor or civil process for the employee, which in some cases can be a criminal case depending on the magnitude of the event that occurred. There for, the objective is to reflation about the violation the regulation in the work. The decision on what kind of law should be applied is based on legal rules establishing the extent of the violation of the legal assets. For this determination, it is necessary to obtain the legal value of the violated asset, which is determined by accounting-endorsed certificates, which in turn is governed by inventory valuation methods that weight the value of all goods of similar characteristics in stock. Therefore, in some cases, the value obtained from the accounting is not the actual value of the good according to your purchase invoice.
\end{abstract}




\section{INTRODUCCIÓN}

El derecho como ciencia, estudia las leyes y regulaciones de diferentes órdenes en cualquier país. Dentro de éste, existe el derecho laboral, el cual tiene importancia esencial en la actualidad, porque se producen violaciones, hurtos, indisciplina laboral que traen consigo la aplicación de leyes jurídicas a los trabajadores o directivos.

De esta manera, se explicita que lesionar los bienes jurídicos de un tercero acarrea una responsabilidad derivada del acto ilegal. Esta relación también se manifiesta en el Derecho Laboral, entre el empleador y el empleado, la que se encuentra regulada en el contrato laboral, convenio colectivo de trabajo y normas jurídicas que rigen dicha relación.

Es frecuente que, en esta relación, se lesione el derecho de una de las partes, pero cuando la lesión se produce al patrimonio de una Empresa Estatal o particular por parte del trabajador, inicia para este un proceso de carácter laboral, civil y que en ocasiones llega a ser penal, en dependencia de la magnitud del hecho ocurrido.

Para la determinación de la clasificación del acto transgresor existen normas jurídicas que delimitan claramente la actuación de los órganos competentes para impartir justicia. El Decreto Ley No. 249 de 23 de julio de 2007 sobre la responsabilidad material y sus normas complementarias: Resolución No.5 de 14 de enero de 2008 del Ministro de Trabajo y Seguridad Social, que aprueba las cifra límites para la escasa entidad; Resolución No. 106 de 2 de mayo de 2008 de la Ministra de Finanzas y Precios referida a los precios para la exigencia de la responsabilidad material.

Por su parte, la Resolución No. 25 de 8 de abril de 2008 del Ministro Presidente del Banco Central de Cuba, que establece el coeficiente de conversión de pesos convertibles a moneda nacional, posibilitan determinar si el daño ocasionado a un objeto es inferior a los 2500 pesos y en el caso de dinero inferior a los 2000 pesos, procede la aplicación de la responsabilidad material por carecer de peligrosidad social, en caso contrario procede realizar la correspondiente denuncia ante los Órganos correspondientes de la Policía Nacional.

Por esta razón, los órganos investigativos policiales, la Fiscalía General de la República y los Tribunales Populares solicitan como primera prueba de la procedencia de la denuncia algún documento que muestre el valor del objeto del delito. No obstante, es práctica, que dicha prueba la constituya un certifico del área contable de los órganos u organismos del Estado, o de las cooperativas o negocios privados, requiriendo como requisito, que el mismo se encuentre firmado y acuñado por la máxima dirección de la Empresa o dirigente del área económica.

Esta forma de demostrar el valor del objeto es usada en todos los casos en los que no se presentan auditorías o comprobaciones económicas, donde los auditores o comprobadores están obligados a aportar los documentos primarios que justifiquen sus alegaciones, y se puede constatar el valor real del objeto a través de facturas, conduces, Inventarios cheques u otros documentos acreditativos de este particular.

De esta manera los delitos contra la economía nacional o los delitos contra el patrimonio; que no requieren de la intervención de una acción de control; en los que solo se realiza una denuncia directamente en la Policía por no ser un hecho complejo, se aporta a las actuaciones policiales un certifico del valor del objeto, según conste en los asientos contables de la Empresa. Pero este valor no siempre es el real del objeto, sino que es una asignación contable que pudiera distar en gran medida del valor original debido al método de valoración de inventario que utilice dicha organización.

Estas reflexiones que se realizan desde la práctica laboral del derecho, cobran particular interés como contenido de las asignaturas de Derecho como carrera, para la formación de abogados y la necesidad de profundizar en las diferentes situaciones que se producen en los centros laborales del país. Por eso, la necesidad de profundizar en otros documentos de las empresas. Como métodos fundamentales se utilizaron: los métodos de análisis y síntesis, inducción deducción y los de valoración de inventarios.

\section{DESARROLLO}

Los métodos de valoración de inventarios consisten en técnicas para otorgar valor en términos monetarios a las unidades en un almacén determinado, con el objetivo de conocer el coste de sus inventarios, para determinar el valor de las existencias finales y el de las mercancías vendidas. Por lo tanto, los métodos de valoración de inventarios son una herramienta que nos va a permitir saber el valor de nuestro inventario en unidades monetarias y el coste de los bienes que se han vendido a lo largo del ciclo de explotación.

Existen diversos métodos de valoración de inventarios generalmente aceptados y utilizados: 
- FIFO: First-in, first-out significa que el primer bien que entra al almacén es el primer bien en salir de él, es decir, primero se van vendiendo las unidades de mayor antigüedad.

- Coste medio ponderado: Mediante este método se establece una media del coste de las unidades. Se calcula dividiendo el coste de las unidades entre el total de unidades en el inventario, obteniendo un valor promedio de todas las unidades de similar característica.

- LIFO: Años atrás estaba permitido el método LIFO, last-in, first out significa lo contrario al método FIFO, consiste en que las existencias que han entrado de último en almacén, son las primeras en salir. Con este método, el coste de las mercancías vendidas es mayor y las existencias inventariadas están calculadas a precios más bajos, dando lugar a un menor beneficio (es por ello que no se permiten este método).

En el método FIFO las existencias que primeramente han entrado en el almacén, serán las primeras en salir. En épocas inflacionistas, las mercaderías que entran en último lugar estarán valoradas a un mayor importe porque su precio de compra (o producción) es más elevado. En consecuencia, el coste de las mercaderías vendidas será menor, las existencias finales estarán valoradas más altas y esto ocasiona que la empresa obtenga un mayor beneficio.

El método del coste medio ponderado consiste en hacer una media de las existencias iníciales y las entradas y compras continuas en el almacén ponderándose por sus cantidades. Al contrario del método FIFO, el coste de las mercaderías vendidas y el valor de las existentes en el almacén, es una media de precios, por lo que trata de armonizar y estabilizar las posibles fluctuaciones de los mismos. Este método consiste en hallar el costo promedio de cada uno de los artículos que hay en el inventario final cuando las unidades son idénticas en apariencia, pero no en el precio de adquisición, por cuanto se han comprado en distintas épocas, a diferentes precios o a diferentes proveedores. Para obtener el valor del costo de la mercancía por este método se toma el valor de la mercancía del inventario inicial y se le suman las compras del período, después se divide por la cantidad de unidades del inventario inicial más las compradas en el período.

Una gran parte de las empresas estatales tienen sistemas de gestión contables financieras que gestionan la contabilidad, siendo los más utilizados: Versat Sarasola y SISCONT, estos sistemas están basado en el método del precio promedio ponderado para cuantificar las existencias en inventarios. Por esta razón, los valores de los inventarios en almacén están sometidos a la ponderación de precios y no necesariamente a su precio según factura de compra, lo que puede acarrear consecuencias negativas en la aplicación de las leyes. Por eso, desde otra perspectiva se valoran las consecuencias que se producen.

\section{Consecuencias de la ponderación de precios en la aplicación de las leyes.}

El Decreto Ley 249 del 2007 con sus normas complementarias establece los valores para determinar la procedencia de una responsabilidad material o denuncia policial, en caso de que el trabajador cause un daño al empleador tal como se expuso anteriormente. Por su parte, la Ley 62 de 1987 Código Penal cubano, establece para los delitos patrimoniales, marcos sancionadores que se agravan o atenúan en correspondencia con el monto económico del objeto del delito, algunos de ellos pueden ser cometidos por el empleado valiéndose de sus funciones de trabajo o aprovechando el descuido de otros trabajadores. En dicha legislación se regula el delito de Hurto, en su artículo 322.1: "EL que sustraiga una cosa mueble de ajena pertenencia, con ánimo de lucro, incurre en sanción de privación de libertad de uno a tres años o multa de trescientas a mil cuotas o ambas"

Art. 323: "En el caso previsto en el apartado 1 del artículo anterior, si los bienes sustraídos son de limitado valor, la sanción es de privación de libertad de tres meses a un año o multa de cien a trescientas cuotas o ambas" determinándose por el Consejo de Gobierno del Tribunal Supremo Popular cubano mediante la Instrucción No. 165 de 12 de abril de 2001, que se estiman bienes de limitado valor (artículo 323), aquellos cuya cuantía sea hasta mil pesos.

También presenta figura agravada por el valor del bien el delito de Apropiación Indebida, Art. 335.1.2 del Código Penal cubano: "El que, con el propósito de obtener una ventaja o un beneficio patrimonial ilegítimo para sí o para otro, se apropie o consienta que otro se apropie de bienes que le hayan sido confiados, incurre en sanción de privación de libertad de tres meses a un año o multa de cien a trescientas cuotas o ambas"

2. Si los bienes apropiados son de considerable valor, la sanción es de privación de libertad de dos a cinco años o multa de trescientas a mil cuotas o ambas. La Instrucción No. 165 de 12 de abril de 2001 del Consejo de Gobierno del Tribunal Supremo Popular de Cuba estimo bienes de considerable valor (artículo 335. 2), aquellos de cuantía es superior a dos mil pesos. Como puede observarse, la probanza del valor del objeto es fundamental para determinar, primeramente, ante qué tipo de relación jurídica nos encontramos: laboral o penal, en segundo lugar, para determinar la calificación del tipo penal, y, por último, para determinar la responsabilidad civil derivada del acto antijurídico.

En este sentido, la mera certificación del valor del objeto dañado o sustraído por parte del área económica o la dirección de un actor económico, no es prueba suficiente para establecer el valor legal del mismo, por estar basado dicho 
documento, en el método de valoración de inventario coste medio ponderado. Para ello, sería necesario obtener como medio de prueba, el documento primario que avala la transacción económica, ya sea un conduce, factura u otro documento de los utilizados en el comercio donde se plasme el precio original de cada objeto.

Como ejemplo de lo anterior se hace referencia a una entidad económica, donde en el año 2017 recibió cierta cantidad de una materia prima a un precio de 1000 pesos en moneda nacional, la cual permaneció en almacén hasta el año 2019 , momento en que entró al almacén similar materia prima proveniente de otro proveedor con un valor de 2000, lo que implicó que se duplicara el valor de la materia prima inicial al ponderar los precios de ambas materias primas.

En estas condiciones la materia prima recibida en el 2017 caducó en almacén por incumplimiento de normas técnicas existentes y de funciones propias de un trabajador. Siendo certificado por el área económica un valor que sobrepasaba la escasa entidad para aplicar la responsabilidad material, por lo cual se decidió realizar la correspondiente denuncia a los órganos policiales. Durante las investigaciones internas para la presentación del expediente a la Policía, el consultor actuante se percató mediante factura, del valor real de la materia prima, por lo cual decidió la no procedencia de la denuncia, pues estaba en los marcos de la aplicación de la responsabilidad material. Casos como estos y otros, traen consigo violaciones laborales en diferentes entidades, lo que permite la detección de hurtos, mal manejo de documentos, ventas ilícitas, etc.

\section{CONCLUSIÓN}

Las reflexiones derivadas de este artículo permiten concluir que para la formación de las nuevas generaciones de abogados, resulta vital dominar las certificaciones del valor de los bienes jurídicos dañados, sustraídos o desaparecidos, en entidades económicas por las administraciones o direcciones contables financieras, las cuales han estado basadas en el valor que refiere el submayor de inventario que brindan los sistemas de gestión contables financieros computarizados, que a su vez están diseñados bajo el método coste medio ponderado.

Por esta razón, cabe la posibilidad de que varios casos de afectaciones económicas a entidades por parte de trabajadores, han sido denunciados a las autoridades policiales, lo que implica procesos laborales o penales basados en un valor que ha sido otorgado por inventivas del hombre dentro de la ciencia contable y no por la realidad productiva que otorga precios en correspondencia con los costos de producción.

Por tal razón se hace necesario, establecer en el ordenamiento jurídico cubano la probanza del valor del objeto basado en el coste real del mismo demostrado por el documento que ampara su trasiego económico. En caso de que existiere un perjuicio para la entidad económica por diferencia de valor que afecte a la contabilidad, podría valorarse el resarcimiento de perjuicios económicos u adoptarse otra solución contable, siendo este otro tema para dedicarle un estudio más profundo.

\section{BIBLIOGRAFÍA}

1. Decreto Ley No. 249 de 23 de julio de 2007

2. Gálvez Puebla, Iracema. (2009). La ejecución de la responsabilidad civil derivada del delito en Cuba. Tesis de doctorado. Universidad de La Habana.

3. González, Aguilera Tania e Irene Gutiérrez Pérez. (2012). Los delitos económicos y el proceso penal cubano. Disponible en http://www.gmconsulting.pro/blogideasparasunegocio/metodos-de-valoracion-de-existencias/. Revisado 20 de octubre 2019

4. Iriarte Ramírez, Roberto. (2015). Herramientas para el ingeniero industrial. Disponible en https://www.ingenieriaindustrialonline.com/herramientas-para-el-ingeniero-industrial /administraci\%C3\%B3nde-inventarios/m\%C3\%A9todos-de-valoraci\%C3\%B3n-de-inventarios/ Revisado 20 de octubre 2019

5. Ley 62 de 1987 Código Penal Cubano.

6. Ley Procedimiento Penal. 1988.

7. Márquez, Rodríguez, Manuel. Valoración y métodos para el Derecho Laboral. Disponible en http://www.iasesoria.com/cuales-los-metodos-valoracion-existencias/. Revisado 10 de septiembre 2018

8. Resolución No.5 de 14 de enero de 2008 del Ministro de Trabajo y Seguridad Social

9. Resolución No. 106 de 2 de mayo de 2008 de la Ministra de Finanzas y Precios

10. Resolución No. 25 de 8 de abril de 2008 del Ministro Presidente del Banco Central de Cuba.

11. Ribero, García, Danilo. (2007). Disposiciones del Consejo de Gobierno del Tribunal Supremo Popular. Editora Organización Nacional de Bufetes Colectivos ONBC, 2007. 